$\because$ LA-UR- $Q \infty \%: 4$

Title:

STABILITY OF ALERT SURVIVABLE FORCES DURING REDUCTIONS
Author(s):

Submitted to:
LA-UR- $-98-62$

Gregory H. Canavan, P-DO

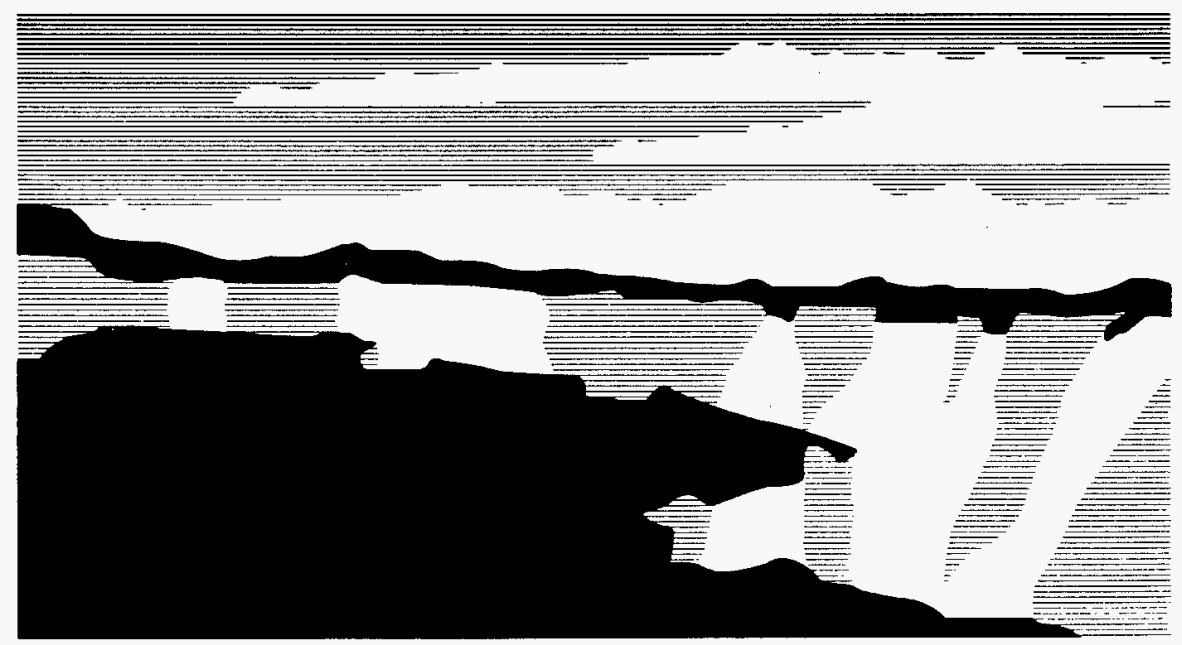

Los Alamos National Laboratory, an affirmative action/equal opportunity employer, is operated by the University of California for the U.S. Department of Energy under contract W-7405-ENG-36. By acceptance of this . 3rticle, the publisher recognizes that the U.S. Government retains a nonexclusive, royalty-free license to publish or reproduce the published form of this contribution, or to allow others to do so, for U.S. Government purposes. The Los Alamos National Laboratory requests that the publisher identify this article as work performed under the auspices of the U.S. Department of Energy. 


\section{DISCLAIMER}

This report was prepared as an account of work sponsored by an agency of the United States Government. Neither the United States Government nor any agency thereof, nor any of their employees, makes any warranty, express or implied, or assumes any legal liability or responsibility for the accuracy, completeness, or usefulness of any information, apparatus, product, or process disclosed, or represents that its use would not infringe privately owned rights. Reference herein to any specific commercial product, process, or service by trade name, trademark, manufacturer, or otherwise does not necessarily constitute or imply its endorsement, recommendation, or favoring by the United States Government or any agency thereof. The views and opinions of authors expressed herein do not necessarily state or reflect those of the United States Government or any agency thereof. 


\title{
STABILITY OF ALERT SURVIVABLE FORCES DURING REDUCTIONS
}

\author{
Gregory H. Canavan
}

The stability of current and projected strategic forces are discussed within a framework that contains elements of current U.S. and Russian analyses. For current force levels and high alert, stability levels are high, as are the levels of potential strikes, due to the large forces deployed. As force levels drop towards those of current value target sets, the analysis becomes linear, concern shifts from stability to reconstitution, and survivable forces drop out. Adverse marginal costs generally provide disincentives for the reduction of vulnerable weapons, but the exchange of vulnerable for survivable weapons could reduce cost while increasing stability even for aggressive participants.

Introduction. This note reviews past, current, and projected strategic forces and discusses their stability within a framework containing elements of current U.S. and Russian analyses. Exchanges between these effective vulnerable and survivable missiles forces are studied with an aggregated, probabilistic model, which optimizes each sides' first and determines each sides' second strikes and costs by minimizing first strike costs. Stability indices for each side are taken to be the ratio of their first and second strike costs; the composite index is the product of the individual indices.

For current conditions, the U.S. is predicted to allocate about half its weapons to the numerous vulnerable Russian missiles. That allocation falls roughly linearly in time as MIRVed missiles are eliminated. Russian allocations are initially a factor of two smaller because of the smaller number of U.S. vulnerable missiles. Beyond START III both forces are single-weapon missiles, so the allocations to missiles are equal and small. Russian first strikes are initially large because of its additional missiles and small allocation to U.S. missiles, which leaves a large number of weapons allocated to military value targets. Soviet second strikes are smaller due to the lesser number survivable Russian weapons. U.S. first strikes offset reductions in weapons by reducing their allocations to missiles. Second strikes fall with reductions in submarines and weapons per survivable missile.

Cost due to damage to self is initially high for both sides due to the large numbers of weapons deployed, but falls to only about twice that of damage to other at the end of the reductions, as inventories fall below objectives. Total first and second strike costs are relatively close for all periods. Stability indices are also closely coupled. Both component indices and the composite index dip slightly and then increase to unity by the end of planned reductions. The total increase in stability throughout the transition is about $5 \%$. Subsequent single-weapon vulnerable missiles indices are stable. 
As force levels drop to the levels of value target sets, the analysis simplifies and concern shifts from stability to reconstitution. At low force levels, first strike costs can be minimizing analytically, producing optimal first strikes that scale directly on the other's vulnerable missiles, inversely on one's own total weapons, and logarithmically on damage preferences, fractionation, and value target sets. This optimal allocation also determines the number of attacking weapons per missile and survival probability, determining the whole exchange. The stability index reduces to a bilinear product of the number of the number of vulnerable missiles and the difference between second and first strikes they could deliver. Stability is approached only for singleweapon missiles. For two or more weapons per missile the stability index falls significantly.

The end point of most arms-control discussions is a mix of a modest number of singleweapon vulnerable missiles with many survivable weapons, which would be stable. In departures from that configuration, increasing the number of single-weapon vulnerable missiles would not alter the stability index, but increasing the number of weapons per vulnerable missile could decrease stability more than it had increased in the earlier stages of arms reductions through the introduction of a modest number of additional weapons. Since survivable forces do not appear in the expression for stability or its derivatives at low force levels, it would not be possible to use them to offset reductions due to additional vulnerable weapons.

The decision to increase or decrease offensive forces should depend on whether they would decrease or increase the cost of first strikes. The marginal first strike cost with respect to vulnerable missiles is positive only for small fractionation and damage preference. Thus, even a non-aggressive participant would see a disincentive for reductions until the number of weapons per vulnerable missile approached unity. This disincentive would have to be offset by other, nonstability considerations. The marginal cost of weapons per missile is negative for all fractionation and damage preferences, which means the attacker should increase their number, as done in the previous decades' buildups. Since the marginal costs of vulnerable missiles and damage preference are generally negative and that for weapons per missile is negative for all values, political pressure would be needed to drive forces toward the small number of weapons per vulnerable missile needed to produce positive stability incentives for further reductions. At low weapon levels, stability is determined by the number and fractionation of vulnerable forces, a situation that cannot be altered by survivable forces and which persists to all lower levels.

For a non-aggressive attacker, the marginal cost of additional survivable weapons is negative, so he should decrease them. Conversely, if he is aggressive, he should increase them. This seems to imply that the attacker follows essentially the same logic in deciding to increase survivable and vulnerable forces. However, offsetting changes in vulnerable and survivable weapons can produce a positive marginal cost per vulnerable weapon and an incentive to reduce them at small fractionation. This exchange of vulnerable for survivable weapons could be 
accomplished while reducing cost and increasing stability for the most aggressive participants. Thus, at low levels, offsetting shifts of vulnerable weapons to survivable ones could provide a positive incentive in marginal cost as well as an increase in stability.

The analysis here assumes that all of the survivable forces can withstand first strike and retaliate. In practice, only the fraction on alert, at sea, or capable of launching under attack would fully meet that assumption. The sensitivity of these results to the extent of non-alert forces is discussed in a companion report

Forces model the reduction in missile forces and weapons from SALT II and STARTII ${ }^{1}$ through START III plus two further reductions suggested by a recent National Academy of Sciences study, ${ }^{2}$ as tabulated in a recent Los Alamos report. ${ }^{3}$ Exchanges are modeled below through an aggregated, probabilistic two-sided exchange model. Below, the two sides are labeled unprime" and "prime for nationality neutrality, although the unprime forces are those of the U.S. and the prime forces are those of Russia. This analysis predicts the first (F) and second (S) strikes unprime could deliver on prime with his $M$ vulnerable missiles with $m$ weapons per missile and $\mathrm{N}$ survivable missiles with $\mathrm{n}$ weapons per missile from his total force of $\mathrm{W}=\mathrm{mM}+$ $\mathrm{nN}$ weapons in any given period. The opponent is labeled "prime," in accord with the symbols used for his forces. Unprime delivers first (F') and second (S') strikes constructed from the $\mathbf{M}^{\prime}$ vulnerable missiles with $\mathrm{m}^{\prime}$ weapons per missile and $\mathrm{N}^{\prime}$ survivable missiles with $\mathrm{n}^{\prime}$ weapons per missile total force of $W^{\prime}=m^{\prime} M^{\prime}+n^{\prime} N^{\prime}$ weapons available to him at that time. ${ }^{4}$

Table I. Vulnerable and survivable missiles and weapons.

\begin{tabular}{|c|c|c|c|c|c|c|c|c|c|c|}
\hline d. regime & $\mathrm{m}$ & & $n$ & $\mathrm{~N}$ & W & $\mathrm{m}^{\prime} \mathrm{l}$ & & $\mathrm{n}^{\prime}$ & $N^{\prime} \quad V$ & \\
\hline 1 SALT II & 2.5 & 1000 & 8.6 & 672 & 8229 & 4.7 & 1400 & 3 & 940 & 940 \\
\hline RT I 1 & 3.2 & 960 & 8.2 & 528 & 7363 & 5.6 & 1090 & 3.5 & & \\
\hline & 3.2 & 755 & 8.1 & 480 & 6304 & 5.2 & 880 & 3.8 & & \\
\hline & 2 & 750 & 8 & 450 & 5100 & 3 & & 3.8 & & \\
\hline & 1 & 500 & 8 & 375 & 3500 & 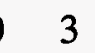 & 500 & 4 & 5 & 350 \\
\hline & 1 & 50 & 5 & 33 & 21 & 1 & & 5 & & \\
\hline & 1 & 20 & 4 & 33 & & & & 4 & & \\
\hline & 1 & 160 & 3.5 & 240 & 1000 & 1 & 160 & 3.5 & 240 & 10 \\
\hline 9 NAS 2 & 1 & 60 & & 240 & 300 & 1 & 60 & & 240 & \\
\hline
\end{tabular}

The SALT II forces are retained as an indication of the residual forces from previous offensive buildups. The total number of weapons on each ICBM launcher is summed over all launcher types $\mathrm{i}$, to give $\sum_{\mathrm{i}} \mathrm{m}_{\mathrm{i}} \mathrm{M}_{\mathrm{i}}$; The total number of ICMB launchers is summed to give $\mathrm{M}=$ $\Sigma_{\mathrm{i}} \mathrm{M}_{\mathrm{i}}$; Then their ratio gives $\mathrm{m}=\sum_{\mathrm{i}} \mathrm{m}_{\mathrm{i}} \mathrm{M}_{\mathrm{i}} / \sum_{\mathrm{i}} \mathrm{M}_{\mathrm{i}} \approx 2.5$, the average number of weapons per ICBM launcher, which is used as the average number of weapons on vulnerable missiles. ${ }^{5} \mathrm{~A}$ similar calculation determines the number of weapons on all SLBM launchers, $\sum_{i} n_{i} N_{i}$; the total number 
of SLBM launchers, $N=\sum_{i} N_{i}$; and $n=\sum_{i} n_{i} N_{i} / N \approx 8.6$, which is used as the average number of weapons per survivable missile. This process is also used with Treaty primed forces to determine average number of prime (Russian) weapons and launchers. This process is repeated with the objective forces for each of the three stages of START I and two of START II to determine the average forces in the next five periods given in Table $\mathrm{I}^{6}$

The START III forces shown reflect a mid-range option with a significantly reduced number of single-weapon ICBMs and a total of 2484 weapons, of which 940 would be carried by aircraft. These aircraft-borne weapons are not accounted for in the analysis below, although they could be within this framework, because aircraft are thought to be too slow to participate in first strikes and inadequately survivable to participate in second strikes under projected conditions.

The two options labeled NAS 1 and 2 are two options suggested in the National Academy of Science Study, which represent successive reductions to 1,000 and 500 weapons from the 1,500 levels likely in START III. The former is to account for other powers; the latter for some core deterrent. The forces shown are not precisely the levels suggested by the NAS, as their assumptions of a largely SLBM deterrent with only a fraction of the submarines at sea would have resulted in an increase in the fraction of vulnerable missiles, which hardly seems intended.

Exchanges. Exchanges between equal missile missiles forces can be modeled in terms of the first and second strikes each side could deliver. That analysis can be extended to unequal forces by treating the strikes $F$ ' and $S$ ' that the second side forces (denoted by primes for simplicity) could deliver. This prime-unprime notation is nationality neutral, but for the specific comparisons here, the unprime symbols refer explicitly to U.S. forces and the prime symbols refer to S.U. and then Russian forces. At any time, unprime (U.S.) has M vulnerable missiles with $\mathrm{m}$ weapons each and $\mathrm{N}$ survivable missiles with $\mathrm{n}$ weapons each, and prime (Russia) has $\mathrm{M}$ ' vulnerable missiles with $m$ ' weapons each and N' survivable missiles with n' weapons each. If unprime is the first striker and a fraction $f$ of his weapons is directed at prime's vulnerable missiles, unprime's first strike on value targets is

$$
\mathrm{F}=(1-\mathrm{f})(\mathrm{mM}+\mathrm{nN}) \text {. }
$$

The average number of weapons delivered on each of prime's vulnerable missile is

$$
\mathrm{r}=\mathrm{f}(\mathrm{mM}+\mathrm{nN}) / \mathrm{M}^{\prime} \text {. }
$$

For $\mathrm{r}$ large, their average probability of survival is approximately ${ }^{7}$

$$
\mathrm{Q}^{\prime} \approx \mathrm{q}^{\mathrm{r}}=\mathrm{e}^{\mathrm{fW} \ln \mathrm{q} / \mathrm{M}^{\prime}}
$$

where $\mathrm{p}=1-\mathrm{q}$ is the attacking missile's single shot probability of kill. Prime's second strike is

$$
S^{\prime}=m^{\prime} M^{\prime} Q+n^{\prime} N^{\prime} \approx m^{\prime} M^{\prime} q^{r}+n^{\prime} N^{\prime} \text {, }
$$

which is delivered on value, as missiles remaining at the end of the exchange are taken to have no value. The corresponding equations for unprime's second and prime's first strikes can be derived either by repeating the logic from his perspective or simply by conjugating the equations 
above, i.e., interchanging primed and unprime symbols. This simplification of the exchange into one strike by each side emphasizes the deterrent role of the weapons over any possible role in extended engagements in accord with recent strategic decisions. ${ }^{8}$

Costs and indices. These first and second strike magnitudes can be converted into the costs of striking first and second through exponential approximations to the fractions of value targets destroyed. The cost of damage to self when unprime strikes first is

$$
\mathrm{C}_{1 \mathrm{~s}}=\left(1-\mathrm{e}^{-\mathrm{kS}}\right) /(1+\mathrm{L}) \text {, }
$$

where $\mathrm{k} \approx 1 / 1000$ is roughly the inverse of the size of unprime military value target set prime wishes to hold at risk, and $\mathrm{L}$ is a weighting parameter. The cost to unprime of incomplete damage to prime is approximated as

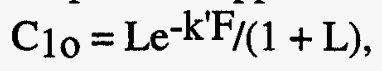

where $k^{\prime} \approx 1 / 1000$ is the inverse of the prime value unprime wishes to hold at risk. $C_{10}$ is small for $F$ large and large for $F$ small. As $\mathrm{C}_{1 \mathrm{~s}}$ and $\mathrm{C}_{10}$ represent damage to different sides, they are formally incommensurate and do not form a proper basis for decision, but it is conventional to use their weighted sum as an approximate total cost for striking first ${ }^{9}$

$$
C_{1}=C_{1 s}+C_{1 o}=\left(1-e^{-k S^{\prime}}+L e^{-k^{\prime} F}\right) /(1+L) \text {. }
$$

The parameter $\mathrm{L}$ represents the attacker's relative preference for inflicting damage on the other and preventing damage to self. This construction of $\mathrm{C}_{1}$ is not unique. ${ }^{10}$ Second strike costs are also composed of damage to self and other, which are approximated by

$$
\begin{aligned}
& \mathrm{C}_{2 \mathrm{~s}}=\left(1-\mathrm{e}^{-\mathrm{kF}}\right) /(1+\mathrm{L}) ; \\
& \mathrm{C}_{2 \mathrm{o}}=\mathrm{Le} \mathrm{e}^{-\mathrm{k}^{\prime} \mathrm{S}} /(1+\mathrm{L}) ;
\end{aligned}
$$

so the total cost for unprime striking second is

$$
\mathrm{C}_{2}=\mathrm{C}_{2 \mathrm{~s}}+\mathrm{C}_{2 \mathrm{o}}=\left(1-\mathrm{e}^{-\mathrm{kF}^{\prime}}+\mathrm{Le}^{-\mathrm{k}^{\prime}} \mathrm{S}\right) /(1+\mathrm{L}) \text {, }
$$

The first and second strike costs for prime can be obtained by conjugation. ${ }^{11}$ It is conventional to use the ratio of first and second strike costs, $\mathrm{I}=\mathrm{C}_{1} / \mathrm{C}_{2}$, as a stability index for unprime, and $\mathrm{I}^{\prime}=$ $\mathrm{C}_{1}{ }^{\prime} / \mathrm{C}_{2}$,' as an index for prime. When they are large, the two sides see no advantage to striking first, although when they are small, there is an apparent advantage, which may be perceived as an incentive to first attack in a crisis. For unequal forces, the product of the stability indices of the two sides is used as a compound index ${ }^{12}$

$$
\text { Index }=\mathrm{I} \times \mathrm{I}^{\prime}=\left(\mathrm{C}_{1} / \mathrm{C}_{2}\right)\left(\mathrm{C}_{1}{ }^{\prime} / \mathrm{C}_{2}{ }^{\circ}\right) \text {, }
$$

in which the smaller of the two indices determines overall stability.

Allocations. Figures 1-4 show the weapon allocations, first and second strikes, costs, and stability indices in each period of the force reduction which are arrived at by numerically minimizing the first strike cost of Eq. (7), or the conjugate equation for prime, for the forces shown in Table I. Figure 1 shows each side's allocation of weapons to the other's vulnerable missiles. The top curve is for the U.S. (unprime) forces, whose allocation is initially about $45 \%$ 
due to the large number of vulnerable Russian missiles in SALT II. The allocation falls roughly linearly in time until period 6, when it takes a sharp drop because of the elimination of MIRVed Russian missiles. At the left, the bottom curve is the Russian allocation, which is initially a factor of two smaller than the U.S.'s because of the U.S.'s smaller number of vulnerable missiles. From period 2 to 5 the two allocations decrease in parallel. In period 6 the drop in $\mathrm{f}$ due to the elimination of MIRVed Russian missiles together with Russia's excess in missile warheads causes the curves to temporarily reverse. Beyond period 6 both forces are singlets, so the allocations to missiles are equal and small.

First and second strikes are shown in Fig. 2. The top curve is the Russian first strike. It is initially large because of Russia's additional weapons under SALT II and small allocation to the lesser number of U.S. vulnerable missiles, which leaves a large number of weapons allocated to value. The Russian first strike falls roughly linearly with the arms reductions. The second curve is U.S. second strike, which is initially large, but falls with the START I reduction in submarines and then START II reduction in weapons per SLBM. The third curve is the U.S. first strike, which partially offsets the reductions in weapons by the reduced allocation to missiles shown in Fig. 1. The bottom curve on the left is the Soviet second strike, which is smaller and flatter through period 6 due to the lesser number of survivable Russian weapons. Although the strikes are diminished by several orders of magnitude by the end of the transition, they could be significant even there, depending on the proximity of value targets to urban areas.

Cost of damage to self and incomplete damage to other for the U.S. are shown in Fig. 3. The top curve is the cost of damage to the U.S. when it strikes second, which is large because of the large vulnerable Russian force. The second curve is the cost of damage to the U.S. when it strikes first and limits the vulnerable Russian forces. The two bottom curves are the costs to the U.S. for incomplete damage to the other when striking first or second, which are close to each other and much smaller than the costs of damage to self in early periods. The costs of damage to self are on the order of 0.6 through the sixth period and then fall abruptly. The costs of incomplete damage to other are small until then and then rise about as rapidly. At period six, the cost of damage to self is about 0.3 and that from incomplete damage to other is about 0.2 . Russia's costs are similar, although its cost for damage to self in striking first is similar to that for striking second and its cost for incomplete damage is appreciable even in early periods.

Total first and second strike costs, which are the sum of Fig. 3's cost of damage to self and other, are shown in Fig. 4. They are relatively close in all periods. The lowest curve is the U.S. cost of striking first, essentially the cost of damage to self in striking first of the previous chart, which is roughly constant at about 0.63 until period six, where it increases slightly due to the shifting allocations discussed below. It then fall to about 0.5 by period 9 , where the cost is about $60 \%$ from damage to self and $40 \%$ from incomplete damage to other. 
Stability indices. Figure 5 shows the component ratio and overall stability indices for each period. The top curve is the Russian index, which starts at about unity due to the limited incentive for preempting survivable U.S. forces, dips slightly in START I, and then increases to unity again by period 7. The second curve is the U.S. index, which starts at about 0.95 due to the larger number of vulnerable Russian weapons, drops to about 0.93 , and then rises rapidly in period six because of the elimination of vulnerable Russian missiles with multiple warheads. The overall index falls from 0.96 to 0.9 during START I-II and then increases by stages to unity by period seven, START III. The subsequently single-weapon vulnerable missile configurations are stable. The total increase in the overall stability index throughout the transition is about $5 \%$.

Attack allocation at low force levels. The stability of configurations subsequent to START, where forces are small enough for costs to be linearized, cab be discussed analytically. First strikes are optimized by minimizing the cost of executing them, ${ }^{13}$ which for unprime amounts to choosing the $f$ that minimizes his first strike cost $C_{1}$. For small forces $(F, S<1 / k)$, that is accomplished by differentiating the linearized version of Eq. (7)

$$
(1+\mathrm{L}) \mathrm{C}_{1}=\mathrm{kS} S^{\prime}+\mathrm{L}\left(1-\mathrm{k}^{\prime} \mathrm{F}\right)=\mathrm{k}\left[\mathrm{m}^{\prime} \mathrm{M}^{\prime} \exp \left(\mathrm{fW} \operatorname{lnq} / \mathrm{M}^{\prime}\right)+\mathrm{n}^{\prime} \mathrm{N}^{\prime}\right]+\mathrm{L}\left[1-\mathrm{k}^{\prime}(1-\mathrm{f}) \mathrm{W}\right],(12)
$$

with respect to $f$, setting the result to zero, and solving for $f$, which produces

$$
f_{O}=\left(M^{\prime} / W \operatorname{lnq}\right) \ln \left(-\mathrm{Lk}^{\prime} / \mathrm{km}^{\prime} \operatorname{lnq}\right) \text {, }
$$

whose conjugate gives prime's optimal first strike allocation. Unprime's $f_{o}$ scales directly on prime's vulnerable missiles, $\mathrm{M}^{\prime}$, and inversely on his own total weapons $\mathrm{W}=\mathrm{mM}+\mathrm{nN}$, as seen in the numerical optimizations above. In a first strike, the distinction between vulnerable and survivable missiles is not significant, so the degree of fractionation of each is unimportant, and only the total $\mathrm{W}$ matters. That the number of weapons allocated to missiles is proportional to the number of missiles, i.e., $\mathrm{Wf}_{\mathrm{opt}} \sim \mathrm{M}^{\prime}$, means that all vulnerable missiles are attacked. The allocation also depends on unprime's damage preference $L$ and prime's weapons per vulnerable missile $\mathrm{m}^{\prime}$. Since $\operatorname{lnq}<1$, it is useful to define $\mathrm{q}=1 / \mathrm{q}>1$, which reduces Eq. (16) to

$$
f_{0}=\left(M^{\prime} / W \operatorname{lng}\right) \ln \left(k^{\prime}{ }^{\prime} \operatorname{lng} / L k^{\prime}\right)
$$

As the argument of the logarithm is near unity, the increase of $f_{o}$ with $m$ ' and decrease with $L$ are strong, as seen above.

Figure 6 compares this analytic allocation with the numerical allocations of the previous sections. At the left, the top curve is the numerical allocation and the bottom curve is the analytic allocation. They differ significantly in early periods, although the number of weapons is so great there that they would not lead to greatly differing indices. They converge by period five, although they cross in period six due to the force imbalance discussed above. For period seven and later they are quite close. That means that the discrepancies are significant at $\sim 2,800$ weapons, but not at $\sim 1,500$ weapons, even though $\mathrm{kW} \sim 1.5$ there. Thus, for a few thousand weapons, the analytic optimization of attacks appears adequate. 
Once the allocation is determined analytically, the number of weapons per missile, survivability probability, and second strikes are as well. At low levels, the forces of Table I are largely symmetric, so it is not necessary to distinguish between unprime and prime forces, and unprimed symbols are used for both. With this simplification and analytic allocation, the average number of weapons per vulnerable missile is

$$
\mathrm{r}=\mathrm{f}_{\mathrm{o}} \mathrm{W} / \mathrm{M}=\ln (-\mathrm{L} / \mathrm{mlnq}) / \mathrm{lnq},
$$

and the survival probability is

$$
\mathrm{Q} \approx \mathrm{q}^{\mathrm{r}}=-\mathrm{L} / \mathrm{mln} \mathrm{q} \text {. }
$$

so $f_{O}, r$, and $Q$ are completely determined by $M / W, L / m$, and $q$. As $r$ and $Q$ are the key parameters in the analysis below, $M / \mathrm{W}$ also drops out of the analysis.

Costs at low force levels can be linearized to simplify the exploration of strikes, costs, and indices to weapons per vulnerable missile $\mathrm{m}$ and damage preference $\mathrm{L} .{ }^{14}$ For small, equal forces, the costs of striking first and second Eqs. (7) and (10) reduce to ${ }^{15}$

$$
\begin{aligned}
& (1+\mathrm{L}) \mathrm{C}_{1} \approx \mathrm{kS}+\mathrm{L}(1-\mathrm{kF})=\mathrm{k}[\mathrm{QmM}+\mathrm{nN}]+\mathrm{L}[1-\mathrm{k}(\mathrm{W}-\mathrm{rM})], \\
& (1+\mathrm{L}) \mathrm{C}_{2} \approx \mathrm{kF}+\mathrm{L}(1-\mathrm{kS})=\mathrm{k}[\mathrm{W}-\mathrm{rM}]+\mathrm{L}[1-\mathrm{k}[\mathrm{QmM}+\mathrm{nN}] .
\end{aligned}
$$

For small $\mathrm{F}$ and $\mathrm{S}$, the stability index is approximately ${ }^{16}$

$$
\mathrm{I}=\mathrm{C}_{1} / \mathrm{C}_{2} \approx 1+\left(\mathrm{C}_{1}-\mathrm{C}_{2}\right)(1+\mathrm{L}) / \mathrm{L}=[(1+\mathrm{L}) / \mathrm{L}] \mathrm{k}(\mathrm{S}-\mathrm{F}),
$$

so that an appropriate index for small forces is

$$
\mathrm{J}=(\mathrm{I}-1) \mathrm{L} /(1+\mathrm{L}) \approx \mathrm{k}(\mathrm{S}-\mathrm{F})=\mathrm{k}(\mathrm{QmM}+\mathrm{nN})-\mathrm{k}(\mathrm{W}-\mathrm{rM}),
$$

which is negative for instability and positive for over stability.

Strikes at low force levels. With the optimal allocation the first strike by either side is

$$
\mathrm{F}=(1-\mathrm{f}) \mathrm{W}=[1-(\mathrm{M} / \mathrm{W} \operatorname{lnq}) \ln (-\mathrm{L} / \mathrm{mlnq})] \mathrm{W}=\mathrm{W}-(\mathrm{M} / \operatorname{lnq}) \ln (-\mathrm{L} / \mathrm{mlnq}) \text {, }
$$

and the second strike is

$$
\mathrm{S}=\mathrm{QmM}+\mathrm{nN} \text {, }
$$

so that the difference is

$$
\mathrm{S}-\mathrm{F}=\mathrm{QmM}+\mathrm{nN}-[\mathrm{W}-(\mathrm{M} / \mathrm{lnq}) \ln (-\mathrm{L} / \mathrm{mlnq})]=\mathrm{mM}[\mathrm{Q}-1+\ln (-\mathrm{L} / \mathrm{mlnq}) / \mathrm{mlnq}] \text {. }
$$

Note that $\mathrm{nN}$, the number of survivable weapons, cancels out, because the number of survivable weapons delivered is the same in first and second strikes. Thus, S - F, and hence the stability index J of Eq. (20), depend only on $\mathrm{mM}$; Q, which is a function of $\mathrm{L} / \mathrm{m}$ and $\mathrm{q} ; \mathrm{L} / \mathrm{m}$; and $\mathrm{q}$.

Stability at low force levels does not depend on the survivable forces, although first and second strikes do. Given the form of $\mathrm{S}-\mathrm{F}$, it is convenient to define the normalized index

$$
\mathrm{j}=\mathrm{J} / \mathrm{kM}=\mathrm{Qm}-(\mathrm{m}-\mathrm{r})=\mathrm{s}-\mathrm{f} \text {, }
$$

where $s=Q m$ and $f=m-r$ are the second and first strikes by vulnerable missiles. This form emphasizes the fact that the index is a bilinear product of $M$ and a function $j$ that does not depend on $\mathrm{M}$ or overall force levels. Figure 7 shows $\mathrm{r}, \mathrm{Q}, \mathrm{f}, \mathrm{s}$, and $\mathrm{j}$ as functions of $\mathrm{m}=1-3$ for $\mathrm{p}=0.8$. The top curve is simply $m$, the total number of weapons available. The next curve is $r$, the 
number allocated to each vulnerable weapon. Since $m=f+r$, i.e., each weapon must be allocated either to value or missiles, $\mathrm{f}$ is the difference between $\mathrm{r}$ and $\mathrm{m}$. The allocation to missiles, $r$, starts at $\sim 0.73$ at $\mathrm{m}=1$ and increases as $\ln \mathrm{m}$, in accord with Eq. (15). Since $\mathrm{r}$ increases only logarithmically with $m, f=m-r$ increases almost as rapidly as $m$. $Q$ falls as $1 / m$, in accord with Eq. (16), so $s=m Q=-L / l n q=$ constant, as seen in the fourth curve. Thus, $s$ approaches $\mathrm{f}$ only for $\mathrm{m} \sim 1$, and $\mathrm{j}=\mathrm{s}-\mathrm{f} \sim 0.3-\mathrm{m}$ falls to large negative values by $\mathrm{m}=3$.

Figure 8 shows these quantities as functions of $m$ for $p=0.6$, i.e., less accurate missiles. Comparison with Fig. 7 shows that this reduction in p requires the allocation of more weapons to missiles to achieve the same damage limiting, which increases $r$, decreasing $f$. It also increases $\mathrm{Q}$, which increases $\mathrm{s}$. Thus, while $\mathrm{j}=\mathrm{s}-\mathrm{f}$ falls, it does so more slowly. And it falls from an initial value of about 0.2 , so that it does not go negative until $\mathrm{m} \sim 1.8$. Thus, decreasing the accuracy of the vulnerable weapons increases stability for all $\mathrm{m}$.

Figure 9 shows these quantities as functions of $m$ for $p=0.8$ and $L=1$, a more aggressive attacker. Comparison with Fig. 7 shows that increasing $L$ roughly reverses $r$ and $f$, as increased preference for damage to other shifts weapons from counter force to counter value attacks. As $\mathrm{Q}$ and $\mathrm{s}$ are increased proportionally, $\mathrm{j}=\mathrm{s}-\mathrm{f}$ experiences offsetting increases in $\mathrm{s}$ and decreases in $\mathrm{f}$, so that the net change is small, and it remains close to Fig. 7.

The current configuration has many missiles and weapons per missiles. These results indicate that its most bothersome feature is its multiple-weapon vulnerable missiles. The difference stability index $J=j k M=(s-f) k M$. Since $s$ and $f$ are independent of $M$, as $M$ is decreased at fixed $\mathrm{m}, \mathrm{J}$ decreases in proportion to $\mathrm{M}$. Alternatively, for any given $\mathrm{M}$, as $\mathrm{m}$ decreases, $\mathrm{j}$ approaches zero, which means that $\mathrm{J}$ approaches stability. Decreasing $\mathrm{p}$ increases the asymptotic value of $j$. Increasing $L$ produces more damage but changes stability little.

This analysis can also be used to assess the impact of increasing $M$ or $\mathrm{m}$. The end point of most arms-control discussions is a mix of a modest number of single weapon vulnerable missiles with many survivable weapons. Figure 7 shows that this configuration would have $j=0$ and hence be stable. From that configuration, increasing the number of vulnerable single weapon missiles would not alter the stability index, as $\Delta \mathrm{J}=\mathrm{j} \Delta \mathrm{kM}=(0) \mathrm{k} \Delta \mathrm{M}=0$ for any $\Delta \mathrm{M}$. However, increasing $m$ would decrease stability, as shown in Figs. 7-9. For the nominal conditions of Fig. 7 , returning to $\mathrm{m}=2$ would decrease $\mathrm{j}$ to $\approx-0.5$, which for $\mathrm{kM} \sim 0.5$ would reduce overall stability to $\mathrm{J} \approx-0.25$, which is larger than the increase in the earlier arms reductions, for a number of additional weapons of $\approx 0.5 / \mathrm{k} \sim 50-100$. The general variation of $\mathrm{j}$ with $\mathrm{m}$ is

$$
\mathrm{dj} / \mathrm{dm}=\mathrm{d}(\mathrm{Qm}) / \mathrm{dm}-\mathrm{d}(\mathrm{m}-\mathrm{r}) / \mathrm{dm}=0-1+\mathrm{d}[\ln (-\mathrm{L} / \mathrm{mlnq}) / \mathrm{lnq}] / \mathrm{dm}=-(1+1 / \mathrm{mlnq}),(24)
$$

which is shown in Fig. 10 for $\mathrm{p}=0.5,0.7$, and 0.9. For $\mathrm{p}=0.5$ and $\mathrm{m}<1.5 \mathrm{dj} / \mathrm{dm}$ is positive, so that increasing the number of weapons per vulnerable missile would increase stability. For larger $\mathrm{p}$, more accurate missiles, the derivative is negative for all $\mathrm{m}$, so that increasing the number of 
weapons would decrease stability for any $M$. Since the number of survivable weapons does not appear in the expression for stability or its derivatives at low force levels, it would not be possible to use them to offset reductions due to additional vulnerable weapons.

Reconstitution. Consistent with the metric used here, the decision to add or delete forces should depend on whether they would increase or reduce the cost of first strikes. The attacker attempts to minimize the first strike cost of Eq. (17), whose derivative with respect to $M$ is

$$
(1+\mathrm{L}) \partial \mathrm{C}_{1} / \partial \mathrm{kM} \approx \mathrm{Qm}-\mathrm{L}(\mathrm{m}-\mathrm{r})=-\mathrm{L}\{1+[\mathrm{mlnq}-\ln (-\mathrm{L} / \mathrm{mlnq})]\} / \operatorname{lnq} \text {. }
$$

Like $\mathrm{j}$, this derivative is the difference between the second and first strikes, but with the first strike weighted by the damage preference $\mathrm{L}$. Figure 11 shows $\partial \mathrm{C}_{1} / \partial \mathrm{kM}$ as a function of $\mathrm{m}$ for $\mathrm{L}$ $=0.5,1$, and $2 . \partial \mathrm{C}_{1} / \partial \mathrm{kM}>0$ for $\mathrm{L}=0.5$ and $\mathrm{m}<1.7$; thus, a positive $\mathrm{dM}$ would give $\partial \mathrm{C}_{1} / \partial \mathrm{kM}$ $\mathrm{d} M>0$, which would increase the first strike cost. Hence, for $m$ and $L$ such that $\partial C_{1} / \partial \mathrm{kM}>0$, the first striker would prefer to decrease vulnerable missiles. Note that the derivative is only slightly positive for $L=0.5$; for other values of $L$, it is negative for all $\mathrm{m}$, which means that the first striker would prefer to increase the number of vulnerable missiles. Even for $L=0.5$, for the $\mathrm{m} \sim 3$ typical of current forces, $\partial \mathrm{C}_{1} / \partial \mathrm{kM}$ is significantly less than zero. That indicates that even a nominally non-aggressive participant would see a disincentive for reducing vulnerable missiles until $\mathrm{m}$ fell below 1.5 , which would have to be offset by other, non-stability considerations.

Given the strong dependence of $\partial \mathrm{C}_{1} / \partial \mathrm{kM}$ on the damage preference $\mathrm{L}$, it is useful to explore that dependence separately in Fig. 12 for the values of $\mathrm{m}$ indicated. For $\mathrm{L}$ small, the derivative is small for all $\mathrm{m}$-although it is positive for $\mathrm{m}$ small and negative for $\mathrm{m}$ large. At $\mathrm{L}$ 1 , the spread is from about zero to -1 . At $\mathrm{L}=-2$, the values range from -1.5 to -5.5 , all of which would induce positive $\mathrm{dM}$, in accord with Fig. 11. Thus, large values of $\mathrm{L}$ do tend to drive the number of vulnerable missiles away from stability.

The derivative of cost with respect to the number of weapons per missile is

$$
(1+\mathrm{L}) \partial \mathrm{C}_{1} / \partial \mathrm{m} \approx \mathrm{kM} \partial(\mathrm{Qm}) / \partial \mathrm{m}+\mathrm{k} \partial(\mathrm{nN}) / \partial \mathrm{m}-\mathrm{Lk}(\partial \mathrm{W} / \partial \mathrm{m}-\mathrm{M} \partial \mathrm{r} / \partial \mathrm{m})
$$

$$
\approx-\mathrm{Lk}[\mathrm{M}-\mathrm{M}(-1 / \mathrm{mlnq})]=-\mathrm{kML}(1+1 / \mathrm{mln} q) \text {, }
$$

which is shown as a function of $\mathrm{m}$ in Fig. 13 for $\mathrm{L}=0.5,1$, and $2 . \partial \mathrm{C}_{1} / \partial \mathrm{m}$ is negative for all values of $\mathrm{L}$ and $\mathrm{m}$. That means that in order to minimize first strike cost, the attacker should always increase the number of weapons on vulnerable costs, which is the trajectory forces followed during the buildup of the previous decades. The derivative becomes more negative for larger $\mathrm{L}$ and $\mathrm{m}$, which means that larger exogenous forces would have to be applied to offset stability considerations there. Overall, the derivatives of first strike costs with respect to vulnerable missiles and damage preference are negative except for a small range in $\mathrm{m}$ and $\mathrm{L}$, and the derivative with respect to weapons per missile is negative for all values, so political pressure is needed to drive forces to the smaller m needed for stability in Figs. 7-10.

Survivable forces. It is possible to differentiate Eq. (17) with respect to $\mathrm{nN}$ to produce 


$$
(1+\mathrm{L}) \partial \mathrm{C}_{1} / \partial \mathrm{knN} \approx 1-\mathrm{L},
$$

which implies that if the attacker is non-aggressive $(\mathrm{L}<1), \partial \mathrm{C}_{1} / \partial \mathrm{knN}>0$, so that he should decrease $\mathrm{C}_{1}$ by decreasing $\mathrm{nN}$. On the other hand, it also implies that if the attacker is aggressive $(\mathrm{L}>1), \partial \mathrm{C}_{1} / \partial \mathrm{knN}<0$, so that he should decrease $\mathrm{C}_{1}$ by increasing $\mathrm{nN}$. On the surface, this result would seem to imply that the attacker follows essentially the same logic in deciding whether or not to increase survivable forces as that used in deciding to increase vulnerable ones.

An alternative view is presented in a one-for-one trade of vulnerable weapons for survivable ones. That is, keep $W$ fixed and change $m$ and $n$ such that $d W=0=M d n+N d N$, or $\mathrm{dn}=-\mathrm{dmM} / \mathrm{N} ;$ then

$$
\begin{aligned}
(1+\mathrm{L}) \mathrm{d} C_{1} & \approx \mathrm{k}[\mathrm{d}(\mathrm{Qm}) \mathrm{M}+\mathrm{dnN}]+\mathrm{L}[0-\mathrm{k}(\mathrm{dW}-\mathrm{Mdr})] \\
& \approx \mathrm{k}[0-\mathrm{dmM}]-\mathrm{Lk}[0-\mathrm{M}(-\mathrm{dm} / \mathrm{mlnq})] \\
(1+\mathrm{L}) \mathrm{d} C_{1} & \approx-\mathrm{kM}(1+\mathrm{L} / \mathrm{mlnq}),
\end{aligned}
$$

which is shown in Fig. 14. In contrast to Fig. 13 for changes in $\mathrm{m}$ alone, offsetting changes in $\mathrm{m}$ and $\mathrm{n}$ can produce a positive $\partial \mathrm{C}_{1} / \partial \mathrm{m}$, and hence an incentive to reduce vulnerable weapons at small $\mathrm{m}$. That occurs at large $\mathrm{L}$. Equation (28) shows that this positive region comes from the derivative of $\mathrm{r}$ with respect to $\mathrm{m} . \mathrm{r} \sim \operatorname{lnm}$, so $\mathrm{dr} \sim \mathrm{dm} / \mathrm{m}$, and $\mathrm{dC}_{1} \sim \mathrm{Ldr} \sim \mathrm{Ldm} / \mathrm{m}$, which is at a maximum for $\mathrm{L}$ large and $\mathrm{m}$ small, as seen. Thus, this exchange of vulnerable for survivable weapons could be accomplished at a reduction of cost and increase of stability for even the most aggressive participants.

Summary and conclusions. This note reviews current and projected strategic forces and discusses their stability within a framework thought to be common to U.S. and Russian analysts. It converts those forces into effective vulnerable and survivable missiles forces and studies exchanges between them using an aggregated, probabilistic treatment of the interaction of the two sides' missile forces, approximations to the first and second strikes each could deliver, and optimal offensive missile allocations between missiles and value based on numerical and analytic minimization of first strike costs. Stability indices for each side are taken to be the ratio of their first and second strike costs; the composite index is the product of the individual indices.

For current conditions, U.S. allocations are about $45 \%$ to missiles, due to the large number of vulnerable Russian missiles. They fall roughly linearly in time until Russian MIRVed missiles are eliminated. Russian allocations are initially a factor of two smaller because of the U.S.'s smaller number of vulnerable missiles. Beyond START III both missile forces are singlets, so the allocations to missiles are equal and small. Russian first strikes are initially large because of Russia's additional missiles and small allocation to the fewer U.S. vulnerable missiles, which leaves a large number of weapons to allocated to value. Soviet second strikes are smaller and less variable due to the lesser number of survivable Russian weapons. U.S. first strikes partially offset the reductions in weapons by reduced allocation to missiles. Second 
strikes are initially large, but fall with the START I reductions in submarines and START II reductions in weapons per SLBM. Cost due to damage to self is high for both sides through START III, after which it falls to a level about twice that of incomplete damage to other as inventories fall below objectives. Total first and second strike costs are relatively close for all periods. The exception is the U.S.'s modest advantage in striking first in early periods.

Stability indices are also closely coupled. Both component indices and the composite dip slightly in START I and then increases to about unity by the end of START III. The U.S. index starts slightly lower due to the larger number of vulnerable Russian weapons, drops, and then rises rapidly to unity with the elimination of vulnerable Russian missiles with multiple warheads. The overall index falls significantly but increases by stages to about unity during START. The subsequent single-weapon vulnerable missiles indices are stable. The total increase in stability throughout the transition is about $5 \%$.

As force levels drop to the levels of value target sets, the analysis simplifies significantly and concern shifts from stability to reconstitution. At low force levels, first strike costs can be minimizing analytically to adequate accuracy. Optimal strikes scale directly on the other's vulnerable missiles, inversely on one's own total weapons, and logarithmically on damage preferences, fractionation, and value target sets. This optimal allocation also determines the weapons per missile and hence their survival probability, i.e., it determines the whole exchange. The stability index reduces to a bilinear product of the number of the number of vulnerable missiles $M$, and $\mathrm{j}$, difference between second and first strikes they could deliver. The first factor is just $\mathrm{M}$; the latter depends only on $\mathrm{m}, \mathrm{L}$, and $\mathrm{p}$. It does not depend on $\mathrm{M}$, overall force levels, or on the survivable forces, which cancel out of the analysis. The allocation to missiles, $r$, increases as $\ln \mathrm{m}$, so the first strike, $\mathrm{f}=\mathrm{m}-\mathrm{r}$, increases $\sim \mathrm{m}$. $\mathrm{Q}$ falls as $1 / \mathrm{m}$, so the second strike, $\mathrm{s}=\mathrm{mQ}=$ $-\mathrm{L} / \mathrm{lnq}=$ constant. Thus, $\mathrm{s}$ approaches $\mathrm{f}$ only for $\mathrm{m} \sim 1$. The stability index $\mathrm{j}=\mathrm{s}-\mathrm{f} \sim-\mathrm{m}$ falls to large negative values.

These results indicate that the most bothersome feature of the current configuration is its multiple-weapon vulnerable missiles, which could be eliminated in several ways. For any $\mathbf{M}$, as $m$ decreases, $j$ approaches zero, which produces stability. The end point of most arms-control discussions is a mix of a modest number of single-weapon vulnerable missiles with many survivable weapons, which would have $\mathrm{j}=0$, which is stable. From that configuration, increasing the number of single-weapon vulnerable missiles would not alter the stability index, because $\Delta \mathrm{J}$ $=\mathrm{j} \Delta(\mathrm{kM})=(0) \mathrm{k} \Delta \mathrm{M}=0$. Increasing $\mathrm{m}$ to 2 would decrease $\mathrm{j}$ to $\approx-0.5$ and overall stability to $\mathrm{J} \approx-$ 0.25 for $\mathrm{kM} \sim 0.5$ or an additional $\approx 0.5 / \mathrm{k} \sim 50-100$ weapons. This decrease would be larger than the increase in stability in the earlier arms reductions. Since the survivable weapons do not appear in the expression for stability or its derivatives at low force levels, it would not be possible to use them to offset reductions due to additional vulnerable weapons. 
The decision to increase or decrease offensive forces should depend on whether they would decrease or increase the cost of first strikes. The marginal first strike cost with respect to vulnerable missiles is positive only for small fractionation and damage preference. There, the first striker would prefer to decrease the number of vulnerable missiles; elsewhere, he would prefer to increase it. For $\mathrm{L}=0.5$ and $\mathrm{m} \sim 3$ of current forces, the derivative is significantly less than zero. Thus, even a non-aggressive participant would see a disincentive for reductions until $\mathrm{m} \sim 1$, which would have to be offset by other, non-stability considerations.

The derivative of cost with respect to the number of weapons per missile is negative for all $\mathrm{L}$ and $\mathrm{m}$, which means the attacker should increase their number-the trajectory followed during the buildups of previous decades. The marginal first strike costs with respect to vulnerable missiles and damage preference are negative except for a small range in $\mathrm{m}$ and $\mathrm{L}$, and the derivative with respect to weapons per missile is negative for all values, so political pressure would be needed to drive forces toward the small $\mathrm{m}$ needed for positive stability incentives.

The marginal cost of additional survivable weapons is negative if the attacker is nonaggressive, so he should decrease them. Conversely, if he is he should increase them. This would seem to imply that the attacker follows essentially the same logic in deciding to increase survivable and vulnerable forces, but offsetting changes can produce a positive marginal cost per vulnerable weapon at small $\mathrm{m}$ and large $\mathrm{L}$, and hence an incentive to reduce vulnerable weapons. Thus, this exchange of vulnerable for survivable weapons could be accomplished at a reduction of cost and increase of stability for the most aggressive participants.

Overall, the trend in past and future forces and indices is captured by a simple exchange model, whose main decision variable, the allocation of attacks to missiles and value, can be determined numerically for large forces and analytically for small. Given that allocation, exchanges, costs, and indices are determined. At small forces, where he concern shifts to reconstitution, optimal allocation can also be used to determine the marginal cost of vulnerable missiles and weapons, damage preference, and survivable weapons. The tradeoffs between them provide some incentive for the reduction of vulnerable missiles at low fractionation, but no incentive for the reduction of vulnerable weapons, unless they are offset by survivable weapon increases. Thus, at low weapon levels, stability is determined by the number and fractionation of vulnerable forces, a situation that cannot be altered by survivable forces and which persists to all lower levels of forces. However, offsetting shifts of vulnerable weapons to survivable ones could provide a positive incentive in marginal cost as well as an increase in stability. This analysis assumes that all survivable forces can withstand a first strike and retaliate. In practice, only the fraction on alert or capable of launching under attack would fully meet that assumption. The sensitivity of these results to the extent of non-alert forces is discussed in a companion report 


\section{References}

1. Treaty between the U.S. of America and the Russian Federation on Further Reductions and Limitation of Strategic Offensive Arms. [START II] (U.S. Government Printing Office).

${ }^{2}$. The Future of U.S. Nuclear Weapons Policy, N.A.S. Committee on International Security and Arms Control (Washington: National Academy of Sciences Press, 1977).

3 . D. Thompson, "The START Treaties: Implementation and Status," Los Alamos National Laboratory report LA-UR-97-2045, May 1997.

4. G. Canavan, "Stability of Unsymmetric Forces," Los Alamos LA-UR-97-1133, March 1997.

5 . D. Thompson, "The START Treaties: Implementation and Status," op. cit., pp. 33-4, Table 1, July $31,1991$.

6. D. Thompson, "The START Treaties: Implementation and Status," op. cit., p. 25, Chart E: Numerical Force Limitations under START I and II.

7. G. Canavan, "Probability of Survival from Multiple Weapon Attacks," Los Alamos report LAUR-97-664, February 1997.

${ }^{8}$. R. Smith, "Clinton Directive Changes Strategy On Nuclear Arms Centering on Deterrence, Officials Drop Terms for Long Atomic War," Washington Post, 7 December 1997.

${ }^{9}$. G. Kent and R. DeValk, "Strategic Defenses and the Transition to Assured Survival," RAND Report R-3369-AF, October 1986.

${ }^{10}$. G. Canavan, "Stability at Symmetric Low Force Levels," report LA-UR-97-1631, May 1996.

11. G. Canavan, "Destabilizing Effects of Perceptions," Los Alamos LA-UR-96-1742, May 1996

12. G. Canavan, "Impact of Differing Metrics on Crisis Stability Analyses," A. Zichichi ed., International Seminar on Nuclear War and Planetary Emergencies, 18th Session: Global Stability Through Disarmament (London, World Scientific, 1993).

13. A. Piontkovsky, "New Paradigm of Strategic Stability," A. Zichichi ed, International Seminar on Nuclear War and Planetary Emergencies (London, World Scientific, 1993)

${ }^{14}$. G. Canavan, "Limits on Linearity of Missile Allocation Optimization," Los Alamos report LA-UR-97-3569, August 1997.

15. G. Canavan, "Stability Issues in Reconstitution by Weapon Addition," LA-UR-97-2690, July 1997, Eqns. (23)-(24).

16. G. Canavan, "Stability Issues in Reconstitution by Weapon Addition," Eqns. (25)-(27). 
<smiles>C1=CCCC1</smiles> 

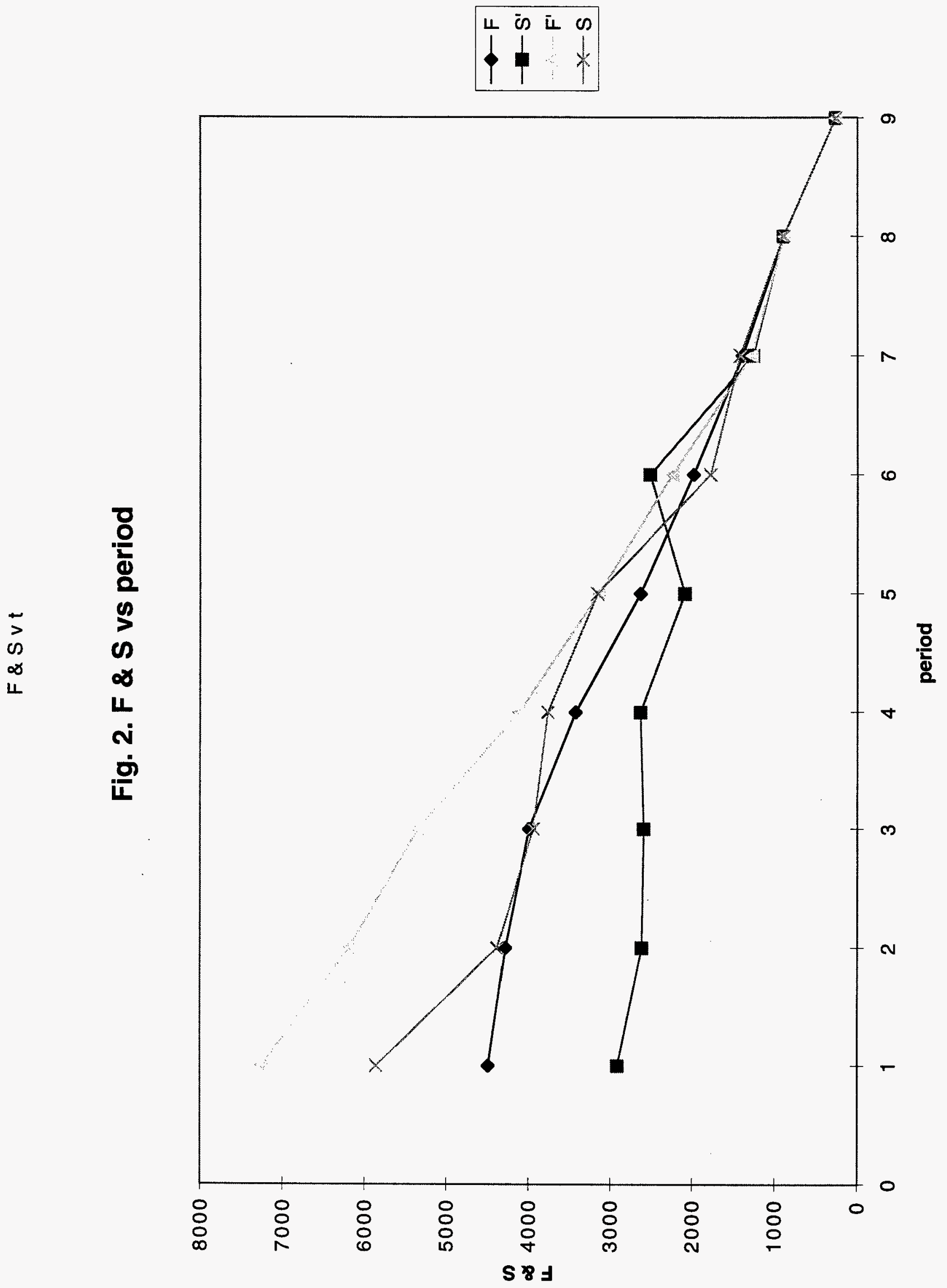

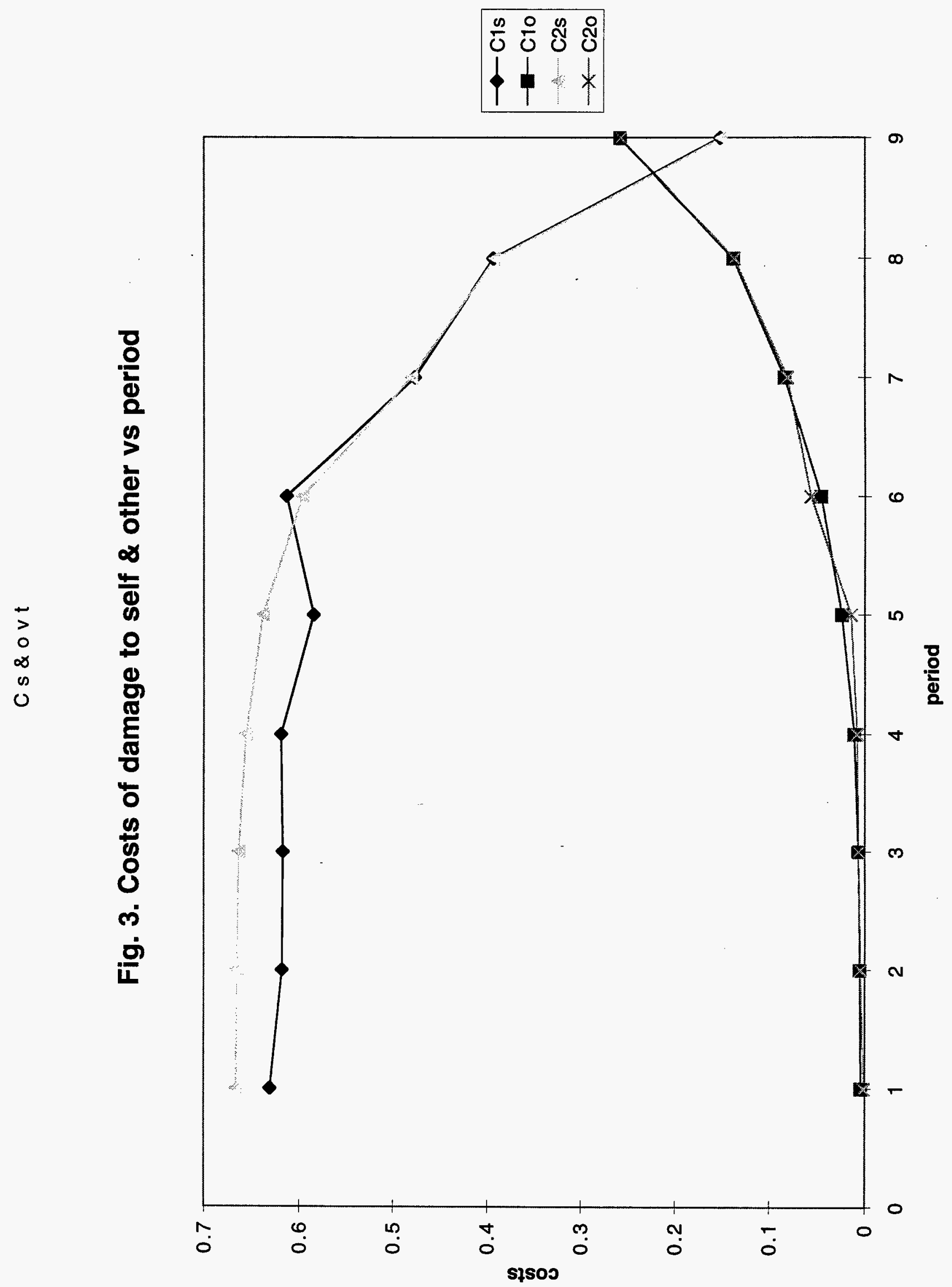


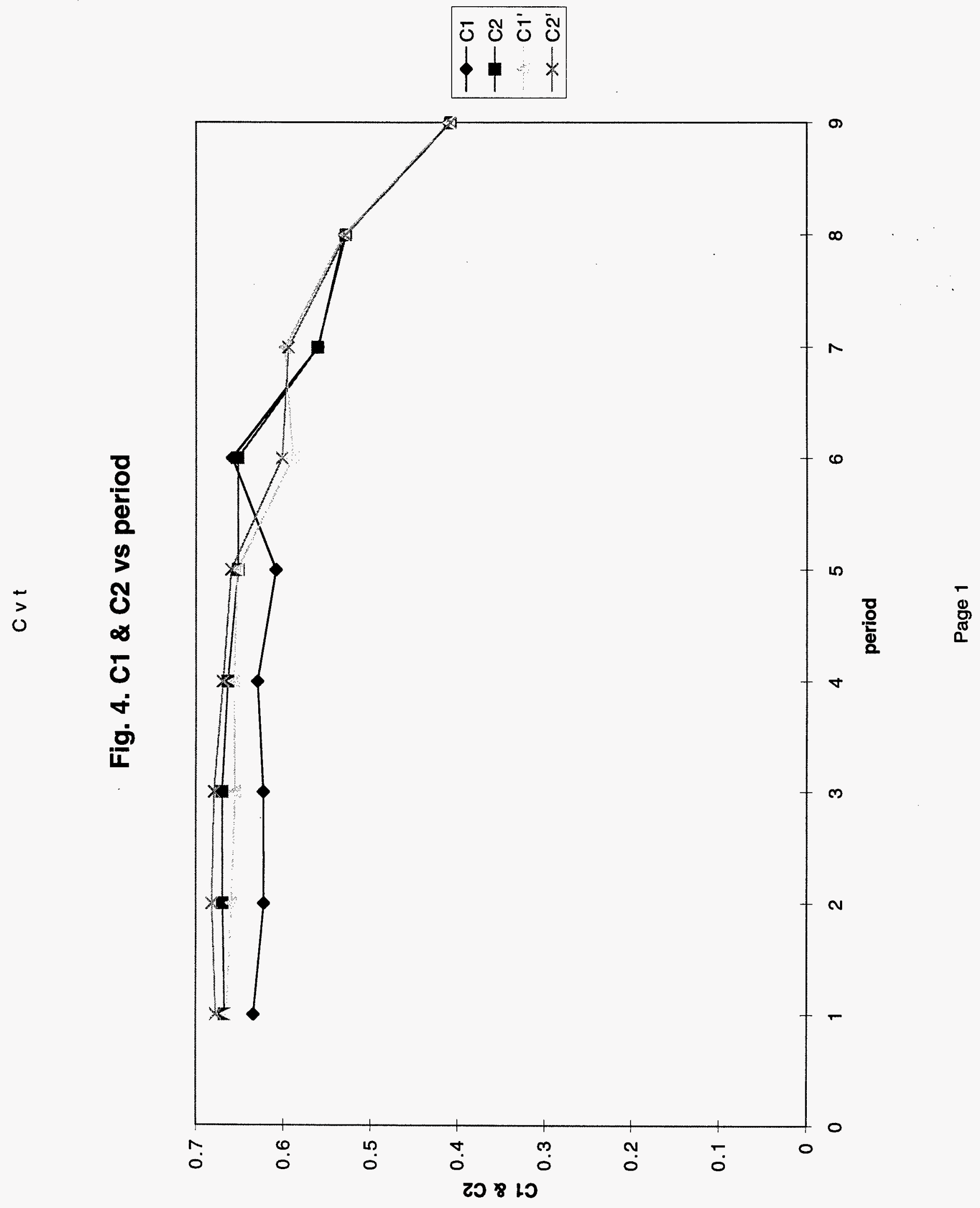



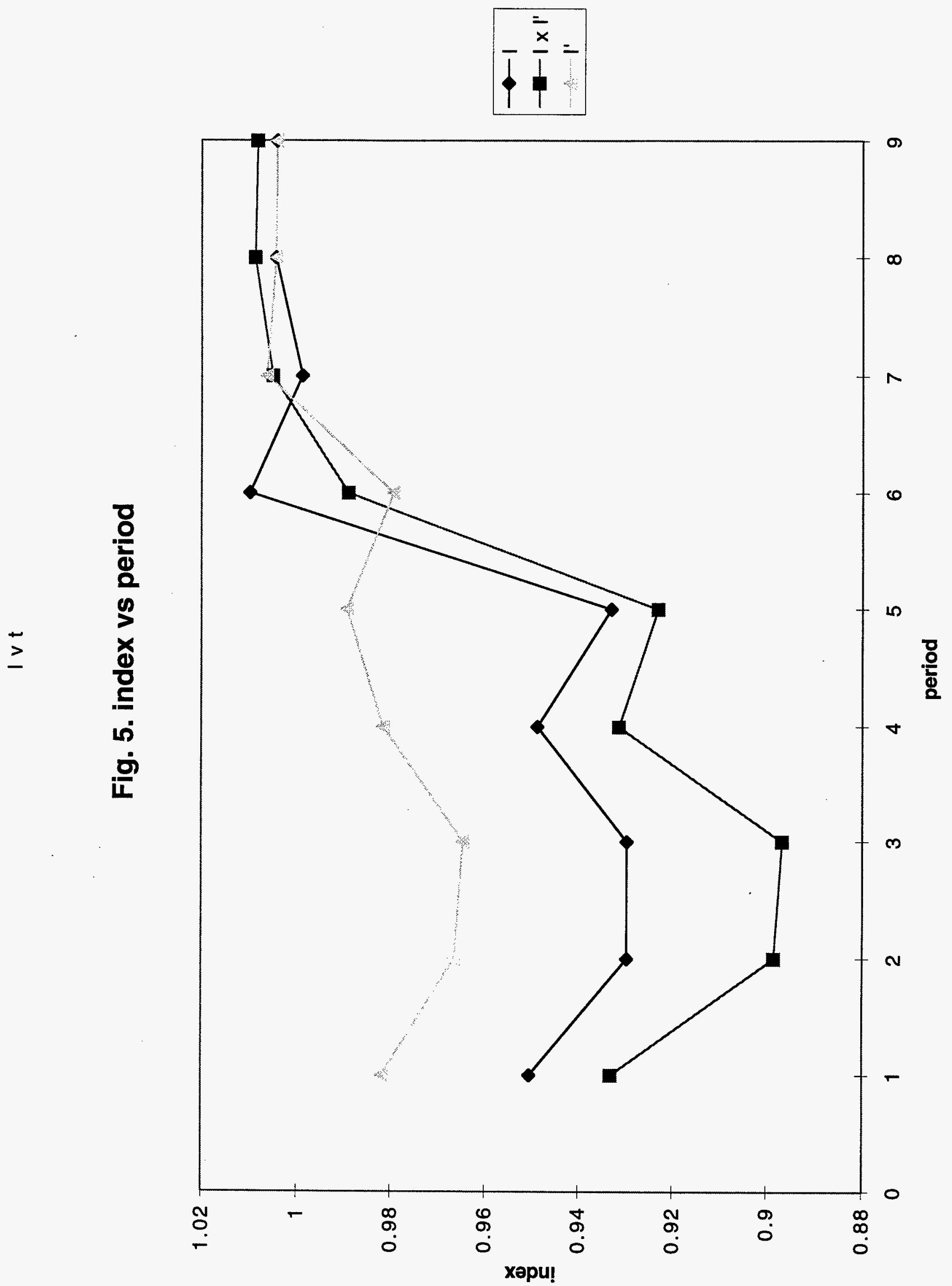


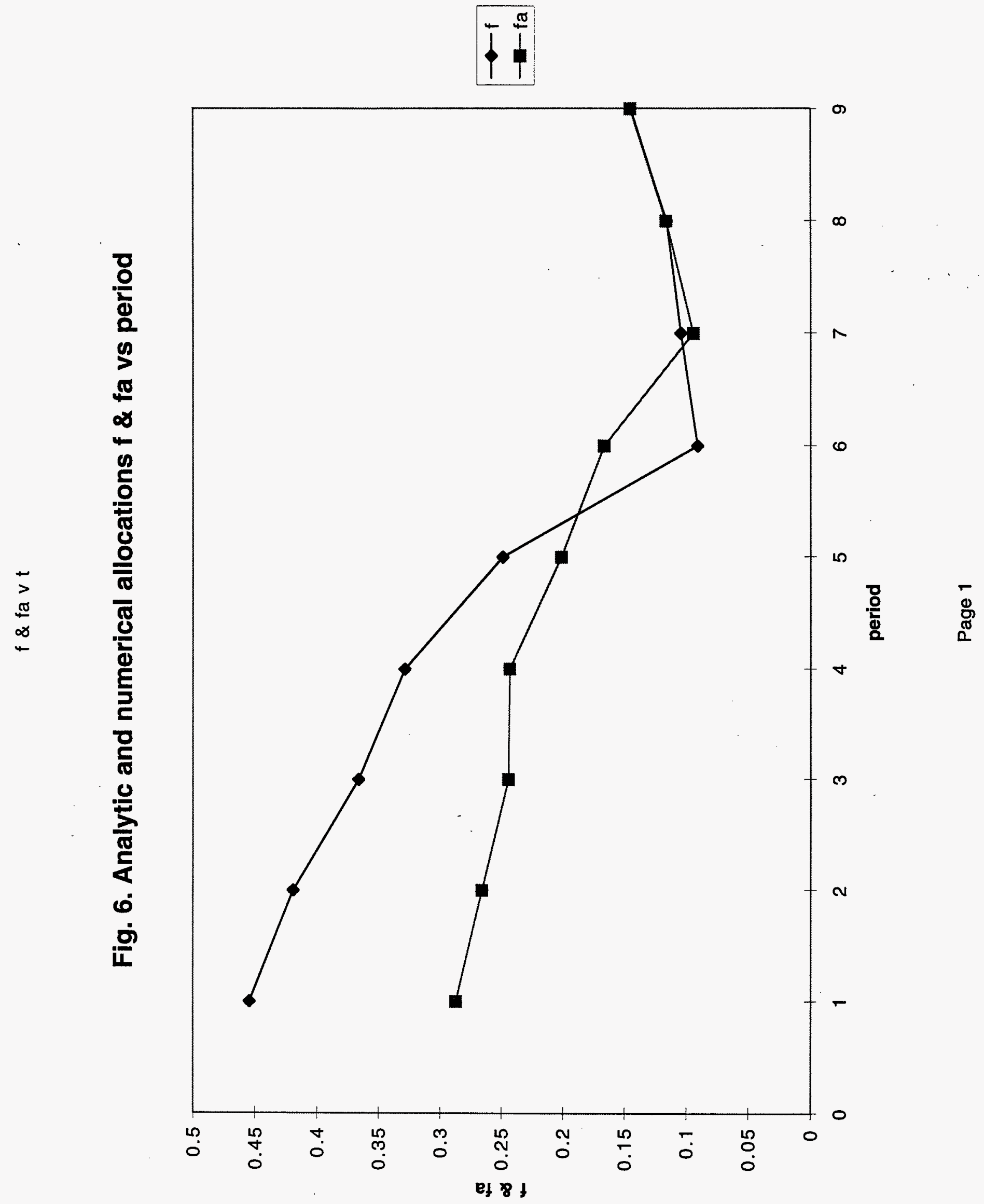




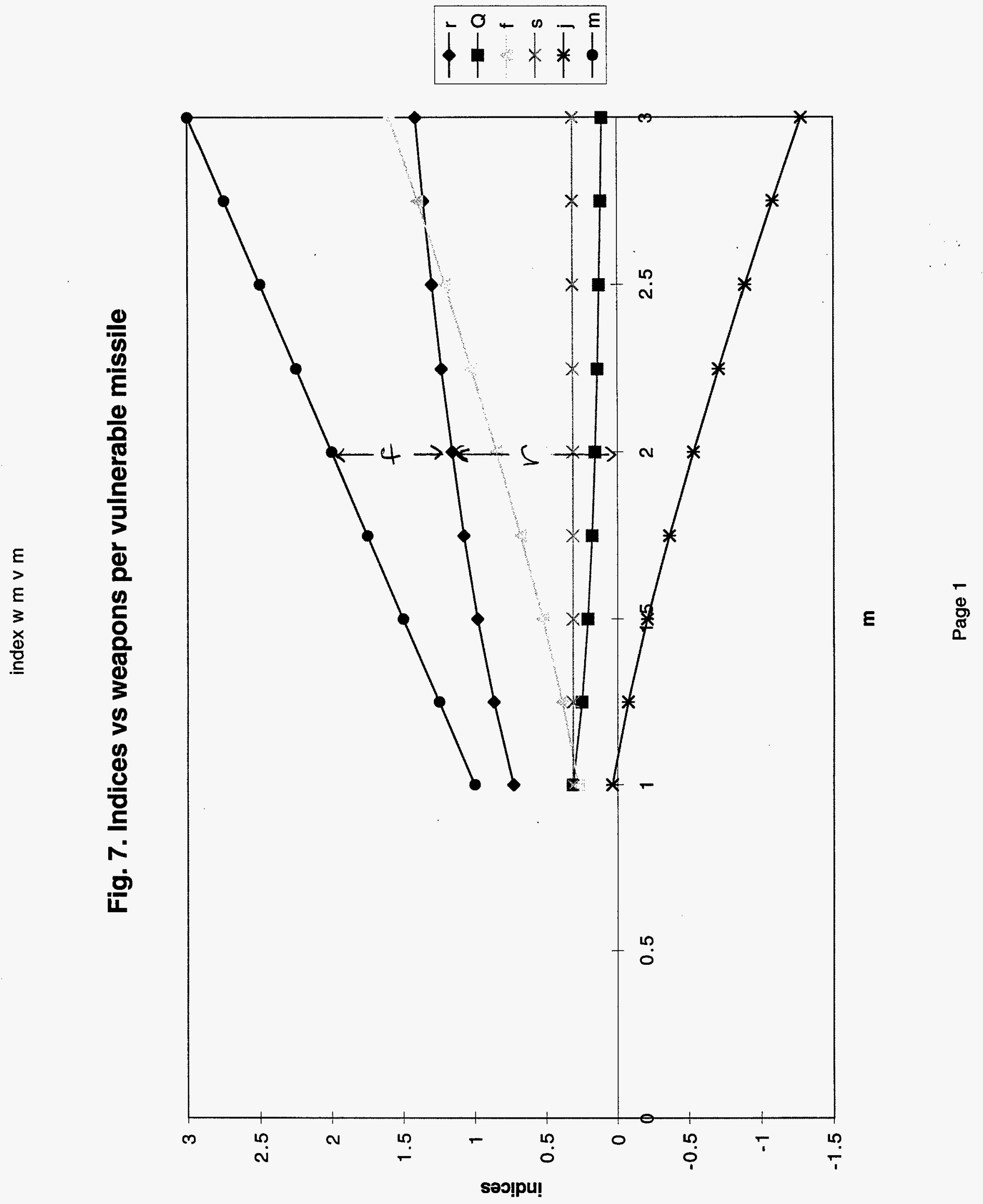




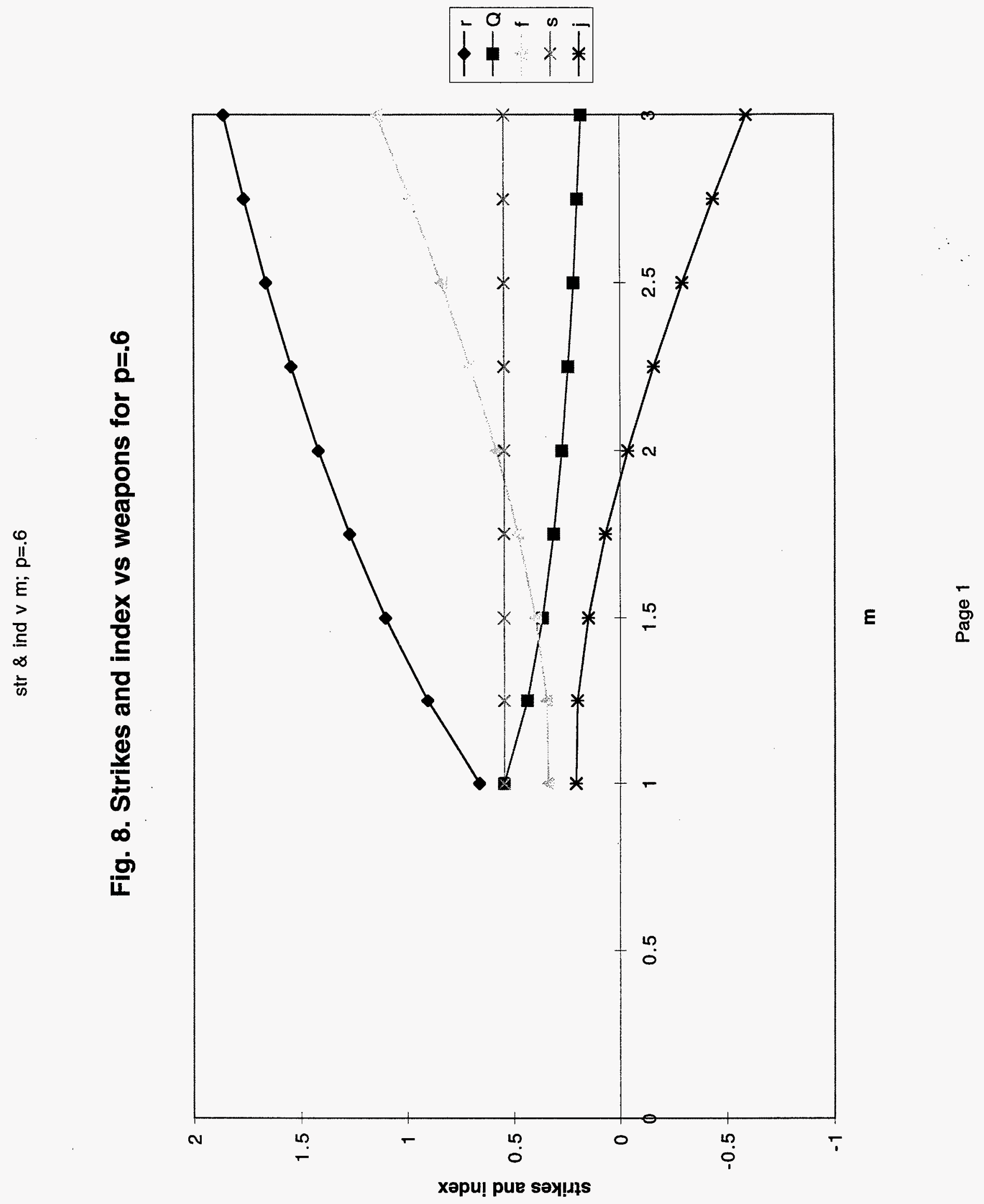




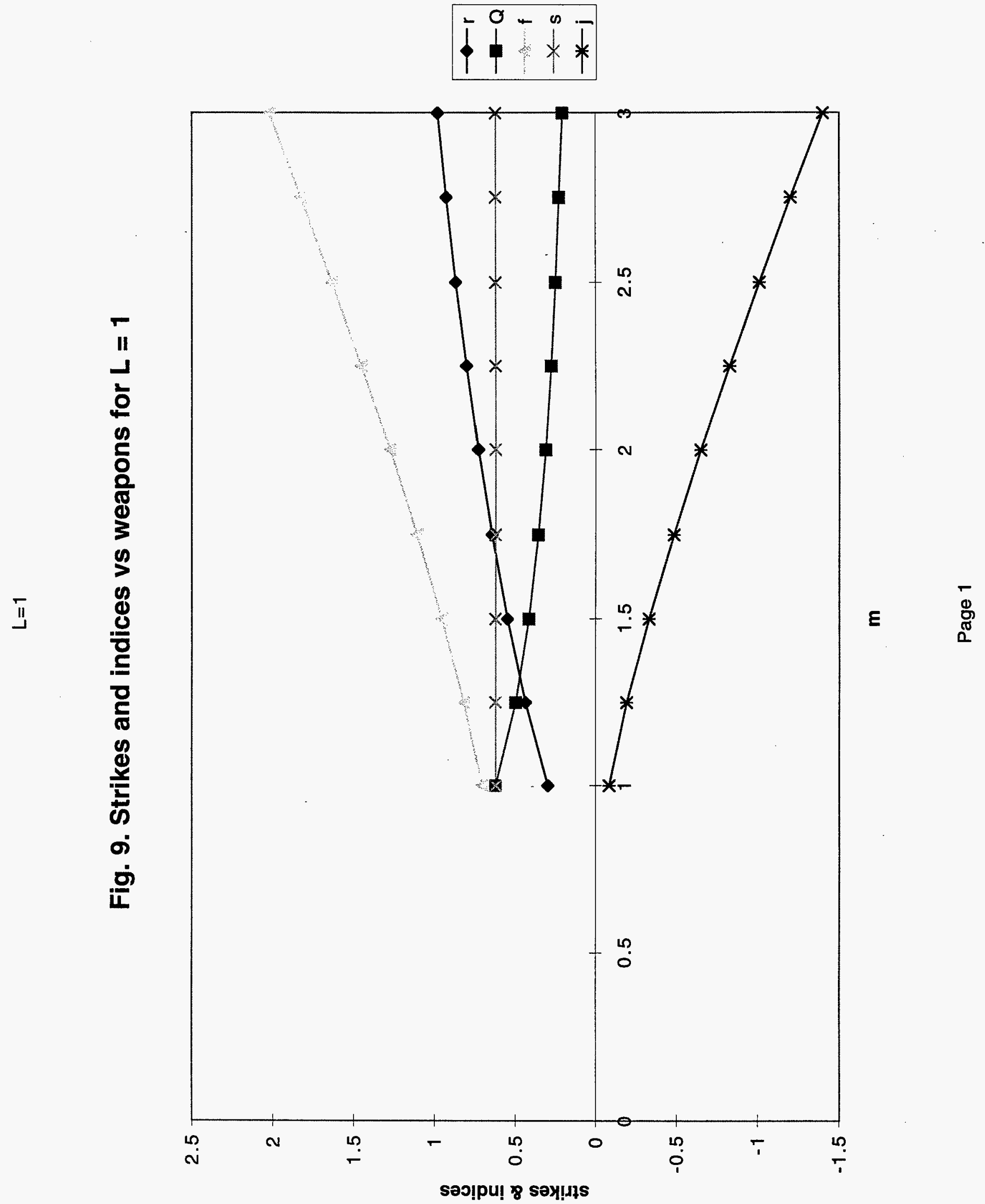




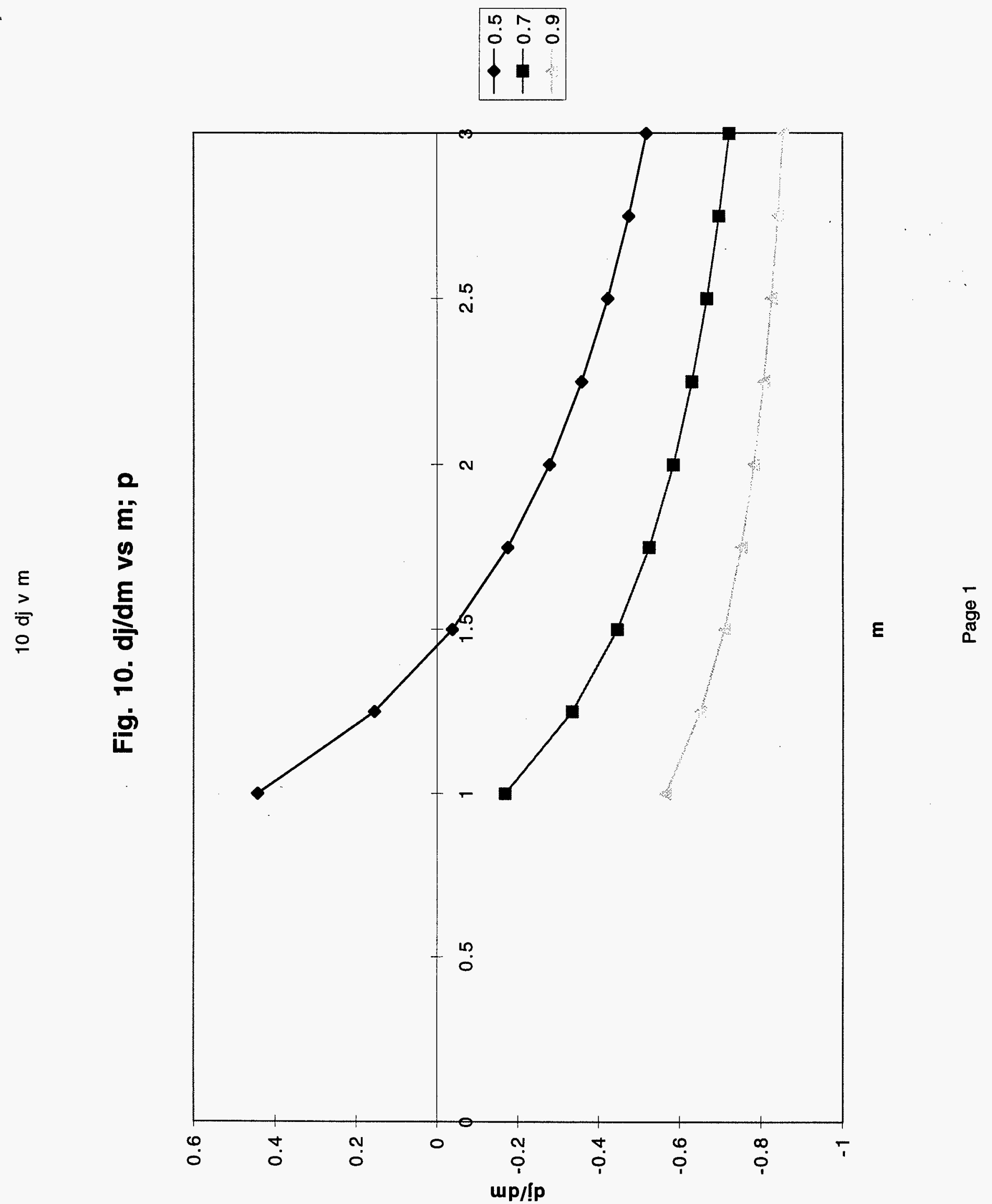




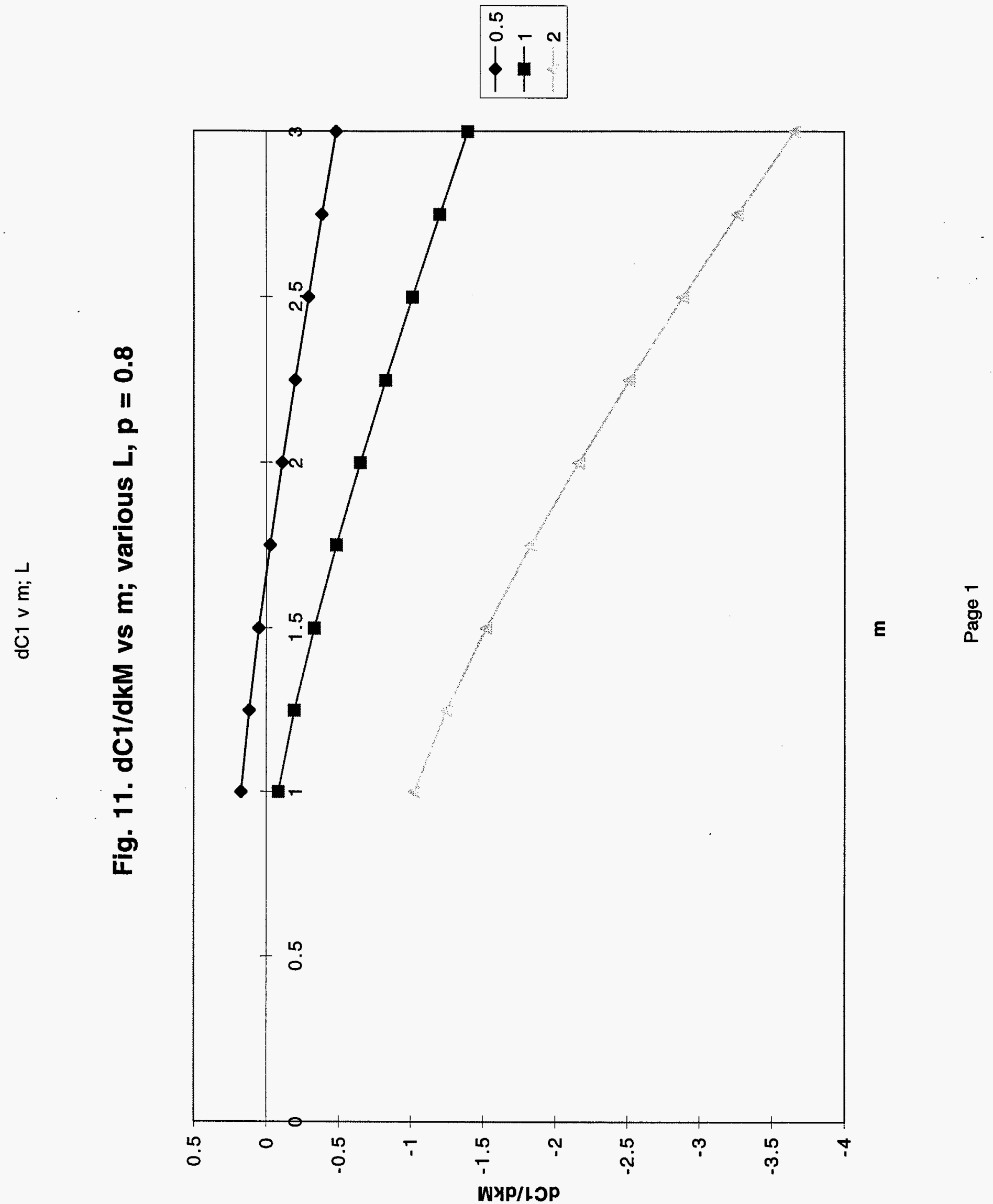




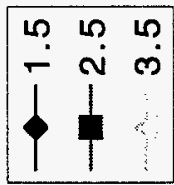
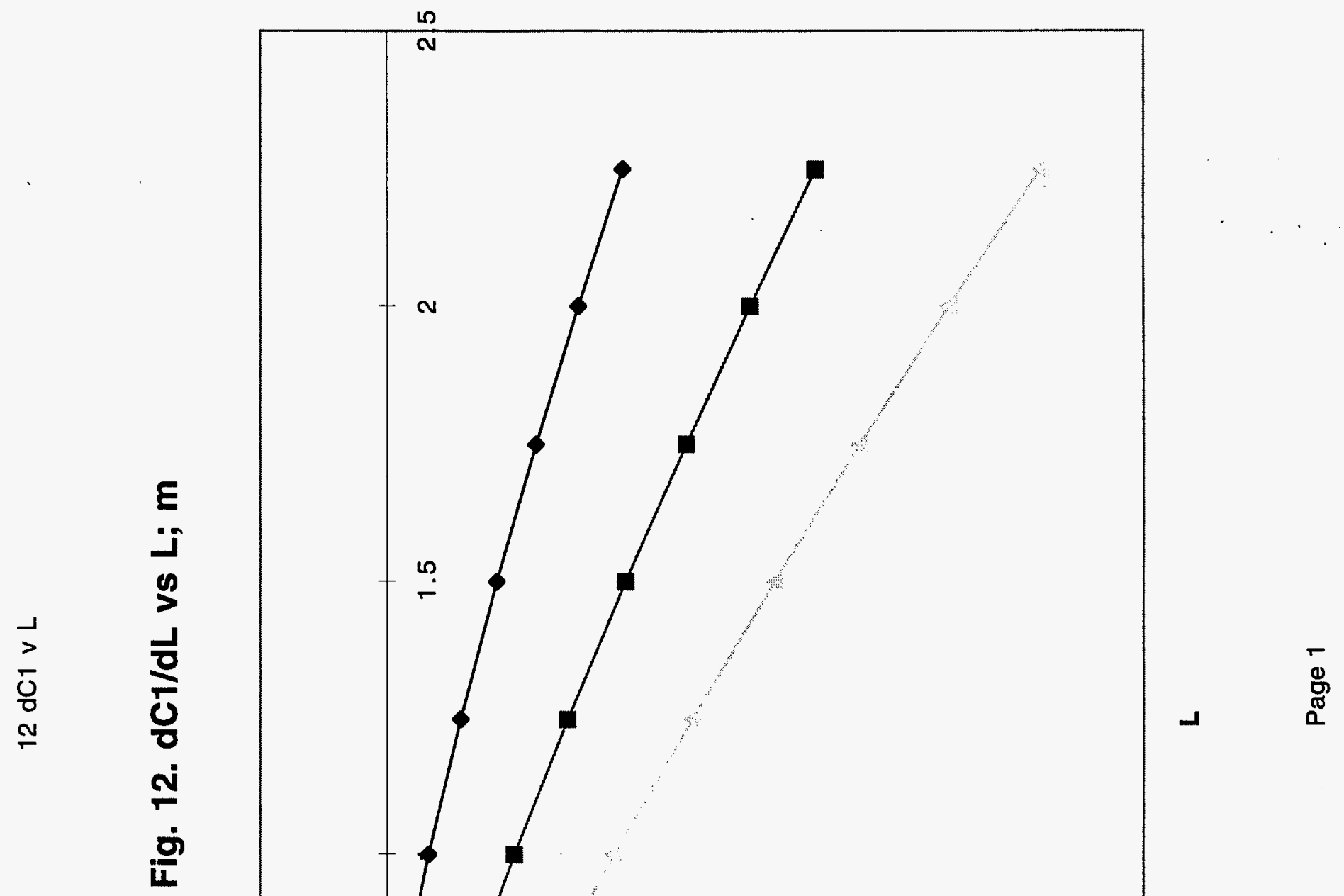


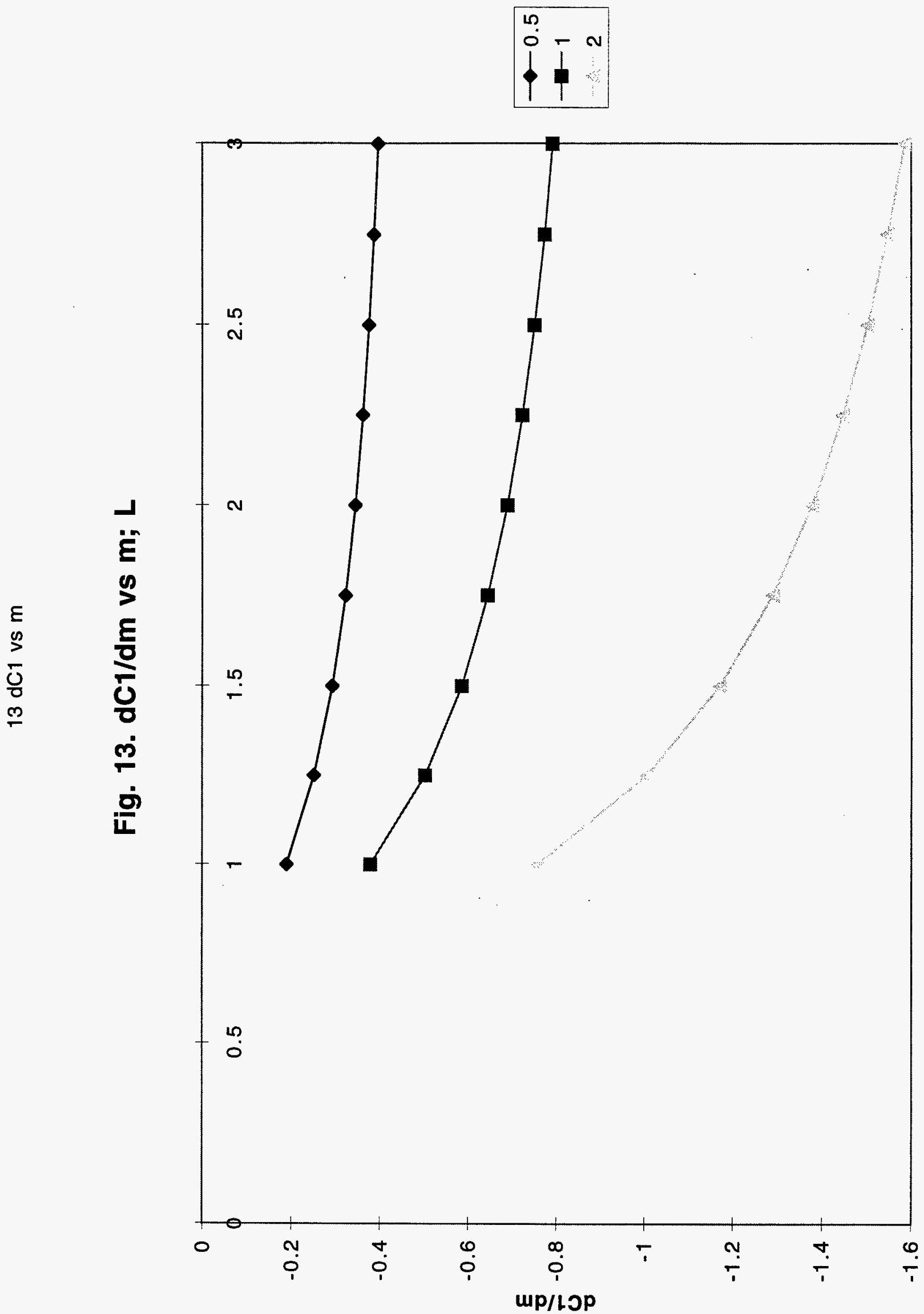

E 


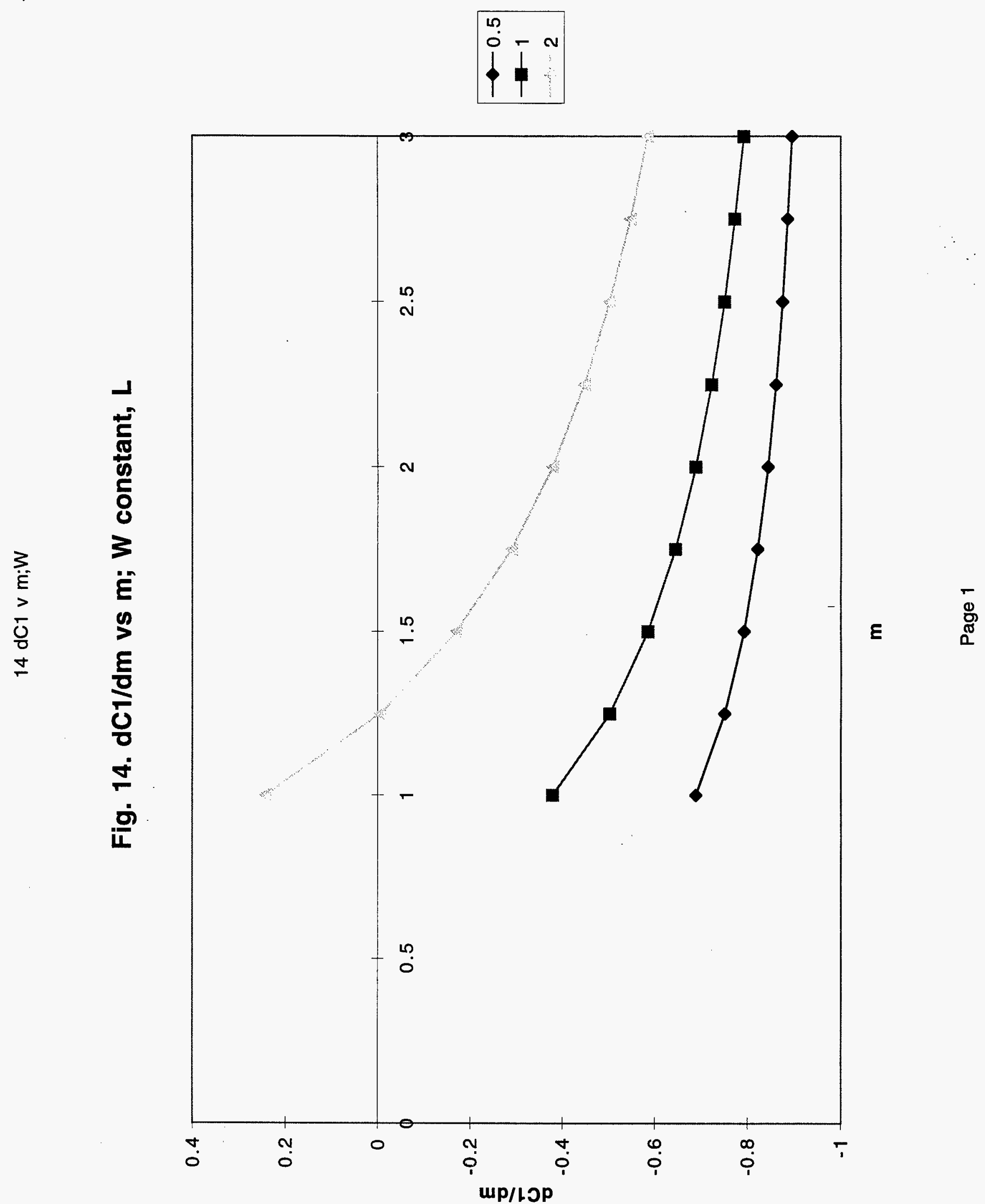


Zeport Number (14) $L A-\cup R--98-62$

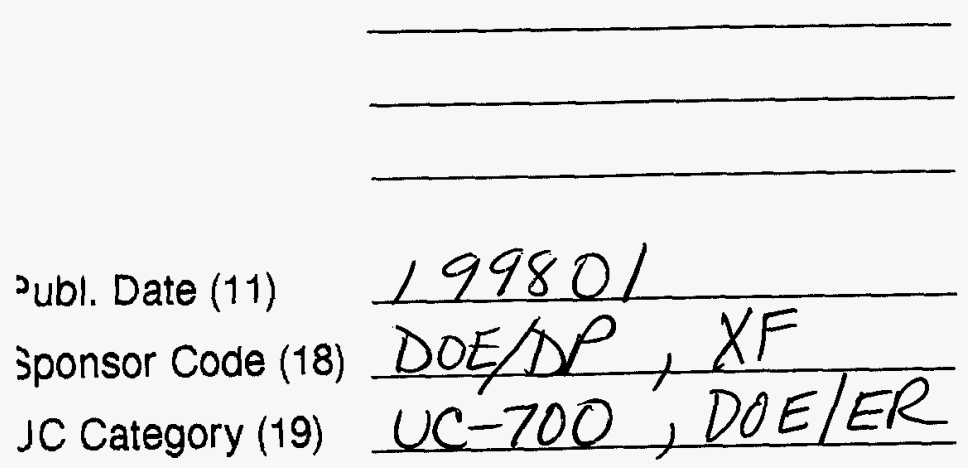

\section{7}

